\begin{tabular}{|c|c|}
\hline $\begin{array}{l}\text { Revue } \\
\text { de I'histoire }\end{array}$ & $\begin{array}{l}\text { Revue de l'histoire des religions } \\
2 \mid 2005\end{array}$ \\
\hline
\end{tabular}

\title{
Dieux des Celtes, Goetter der Kelten, Gods of the Celts
}

Charles-Marie Ternes et Hartmut Zinser éditeurs, Luxembourg, Association européenne pour l'étude scientifique des religions, 2002, $21 \mathrm{~cm}, 284 \mathrm{p}$. ("Études luxembourgeoises d'histoire et de science des religions », 1)

\section{Bernard Sergent}

\section{OpenEdition}

\section{Journals}

Édition électronique

URL : http://journals.openedition.org/rhr/4167

DOI : $10.4000 /$ rhr.4167

ISSN : 2105-2573

Éditeur

Armand Colin

Édition imprimée

Date de publication : 1 avril 2005

Pagination : 235-237

ISBN : 2200-9285-2

ISSN : 0035-1423

Référence électronique

Bernard Sergent, "Dieux des Celtes, Goetter der Kelten, Gods of the Celts ", Revue de l'histoire des religions

[En ligne], 2 | 2005, mis en ligne le 25 janvier 2010, consulté le 22 septembre 2020. URL : http:// journals.openedition.org/rhr/4167 ; DOl : https://doi.org/10.4000/rhr.4167 


\section{COMPTES RENDUS}

Dieux des Celtes, Goetter der Kelten, Gods of the Celts, Charles-Marie Ternes et Hartmut Zinser éditeurs, Luxembourg, Association européenne pour l'étude scientifique des religions, 2002, $21 \mathrm{~cm}, 284$ p. («Études luxembourgeoises d'histoire et de science des religions », 1).

Actes d'un colloque tenu à Luxembourg en 2001, ce volume réunit les communications d'auteurs italien, irlandais, suisse, français, espagnols, autrichien, luxembourgeois et allemands. L'occasion est rare de réunir un aussi grand nombre de nationalités autour de l'exégèse de la religion celtique, et on saura gré au Professeur Ch.-M. Ternes d'avoir à la fois organisé la rencontre et réussi à éditer l'ensemble des textes dans un temps remarquablement bref. Ce qui ne retire rien à la qualité de l'ouvrage.

La dominante y est nettement archéologique. C'est-à-dire que les « dieux des Celtes » étudiés dans l'ouvrage sont avant tout ceux que nous appelons gallo-romains, connus par des inscriptions et des figurations. Dans cet esprit, Alexandre Demandt, de l'Université de Berlin, étudie « le culte des arbres chez les Celtes » et Chiara Tommasi Moreschini revient sur le fameux texte de Lucain sur les « horribles sacrifices » menés par les Celtes dans leurs bois sacrés, mélange, dit-elle, d'intérêt ethnographique et de représentations idéologiques romaines. Francisco Beltrán Lloris et Francisco Marco, de l'université de Saragosse, exposent les connaissances, principalement épigraphiques, sur les divinités celtibères, et Thierry Luginbuehl celles d'Helvétie, en fonction du répertoire qu'il a établi et publié antérieurement aux éditions Epona. Le travail de Gerhard Bauhhens, du Rheinisches Landesmuseum de Bonn, porte sur Hercule, celui de Manfred Hainzmann, de l'université de Graz, sur Taranis, et celui de Michael Altjohann sur Cernunnos. Bien peu de communications ont utilisé le matériel irlandais : Bernhard Maier, de l'Université de Bonn, entreprend la tâche difficile d'étudier les dieux celtiques à la lumière des plus anciens documents linguistiques irlandais, John Carey, de l'université de Cork, étudie les relations entre les dieux Lugus et Nodons, et l'auteur de ces lignes revient sur la question de l'identité supposée du dieu celtique Maponos (gallois Mabon) et du dieu irlandais Mac Óc. 
Enfin, à la lumière de ses fouilles remarquables à Ribemont-sur-Ancre, Jean-Louis Brunaux montre le traitement opposé des corps dans la bataille qui eut lieu en cet endroit au début du $\mathrm{III}^{\mathrm{e}}$ siècle avant notre ère, selon qu'il s'est agi des vainqueurs ou des vaincus.

L'ouvrage témoigne donc avant tout de la vigueur de l'archéologie celtologique allemande et germanophone. Il témoigne aussi de la limitation d'une étude de cette documentation se limitant à l'archéologie. Le travail d'A. Demandt sur l'importance du bois et des arbres chez les Celtes fait certes intervenir quelques données insulaires, comme les quatre arbres sacrés des textes irlandais, l'écriture ogam qui était gravée sur écorce, et invoque aussi des faits toponymiques et folkloriques - mais il « manque » le principal dossier, irlandais, qui est celui de la source de tous les fleuves, dominée par un arbre (noisetier ou coudrier) d'où les fruits tombent dans la source et sont mangés par un saumon qui en acquiert la sagesse... La prise en compte de ce seul dossier eût doublé la taille de sa communication !

De son côté, la conclusion de M. Altjohann, d'une pluralité de figures porteuses de bois de cerf, ressemble plus à un constat d'échec qu'à un acquis. Il est vrai que la question est complexe, puisqu'un personnage identifiable au dieu Lugus (celui de Lugudunum, Lyon, le Lug irlandais, Lleu gallois) est, sur des figurations espagnoles, porteur de cornes, et qu'il est pourtant difficile de l'identifier à Cernunnos : en Gaule, Lugus était, depuis César, identifié à Mercure, et il n'y a pas d'interférences, de doubles épithètes, etc., unissant Mercure et Cernunnos - mais l'on a, aussi, des Mercure cornus.

C'est encore cette identité du Lugus antique qui préoccupe B. Maier dans un passage de sa communication (p. 74) : comme le mot entre dans la formulation de plusieurs noms propres d'individus, et par contre dans une seule formation toponymique - le Lugudunum cité plus haut, porté par une vingtaine de cités en Europe occidentale, Maier pense que le radical ne contient pas le nom d'un dieu, mais un appellatif, un nom commun - et il propose le sens de « guerrier». Lugudunum serait alors « la forteresse des guerriers ». Las! Est-il besoin d'ajouter une signification nouvelle à un terme qui en a déjà pléthore : « corbeau », selon le Pseudo-Plutarque qui raconte le mythe de la fondation de Lugudunum ; «le Lumineux », pour les linguistes qui cherchent l'étymologie du nom de Lugus ; mais encore, selon les auteurs, la «Lune », le « Serment», et le « Marais »? On a envie de crier «Assez! », et le lugus « guerrier» n'ayant d'appui dans aucune langue celtique ou indo-européenne, on doutera de la pertinence de l'analyse de l'A. Lug est un dieu de sommet - les statues colossales du Mercure gallo-romain étaient toutes en hauteur, et c'est sans doute une raison suffisante pour qu'on n'ait pas de ** Luguritum, « Gué de L. », ***Lugumagus, «Plaine de L. », etc.

La contribution de John Carey, elle aussi, se consacre partiellement à ce dieu Lug dont l'importance ne ressort que davantage de cet intérêt multiplié. Son objet est double: d'une part, sachant qu'un mythe gallois fait de 
Llevelys le sauveur de son frère Lludd, attaqué par des fléaux dont Dumézil a montré qu'ils se répartissent sur les trois fonctions indo-européennes, que Lludd est identique au Nuada irlandais et Llevelys certainement à Lug, l'auteur critique certains continuateurs britanniques de Dumézil qui ont voulu retrouver dans les textes irlandais l'équivalent des trois fléaux du texte gallois, et montre - à la suite de Dumézil encore - que ce qui correspond le mieux, en Irlande, au récit gallois, est le motif du coupable, le roi vaincu Bres, qui va alimenter ses vainqueurs (dans le texte gallois, le voleur de toutes les nourritures promet de les rendre). D'autre part, il montre que la parenté entre le héros Find, du cycle des Fenians, en Irlande, et un homonyme, Gwynn, au Pays de Galles, implique l'existence d'un ancien personnage divin Windos, non attesté par des inscriptions antiques, et qui avait des relations familiales étroites avec des dieux précédemment étudiés. C'est donc là un des textes les plus innovants.

En somme, un groupe d'études ponctuelles importantes, qui témoignent de ce que la celtologie est une science en plein développement, et où les découvertes, malgré le caractère hétérogène des sources, ou grâce à lui, vont vite.

Bernard SERGENT,

Centre national de la Recherche scientifique.

Geneviève GoBILlot, La fitra. La conception originelle, ses interprétations et fonctions chez les penseurs musulmans, Le Caire, Institut Français d'Archéologie Orientale, 2000, 146 p. («Cahiers des Annales Islamologiques », 18).

« Acquitte-toi du culte, en hanîf [pur monothéiste], selon la « conception originelle » (fitra) que Dieu a donnée aux hommes, nulle modification à la création de Dieu. C'est la Religion immuable. » (Coran, s. XXX, v. 30) Cette « conception originelle », à laquelle Geneviève Gobillot consacre une étude d'une très grande érudition et pratiquement exhaustive, est une notion fondamentale de la pensée islamique. Aussi démarre-t-elle son analyse en plaçant ce concept dans un contexte contemporain, afin de montrer l'actualité et la permanence de cette notion consubstantielle aux rapports de l'homme à Dieu. L'intemporalité de cette idée dans le langage coranique de tout Musulman d'hier et d'aujourd'hui permet, en effet, une réflexion à plusieurs niveaux. Néanmoins, c'est dans les six premiers siècles de l'islam que l'on peut le mieux étudier ses utilisations multiples, ses diverses interprétations et leur évolution dans le temps, mais aussi sa fonction dans les domaines de la théologie et du « Droit » (fiqh), aspects multiples dont seulement une partie subsistera. En effet, théologiens, traditionalistes, juristes, mystiques et philosophes de l'islam ont eu à cœur d'interpréter le vocable fitra (hapax dans le Coran) et le verbe fatara dont il dérive (qui a, 